economic background to modern public health and social medicine.

Industrialization gained much more momentum in France during the Restoration, although major Frenchspeaking political economists such as Jean Baptiste Say and Simonde de Sismondi had lived through the Revolutionary period as aduits. They shared with Villermé a passion for collecting and analysing social facts of a statistical kind, and had a liberal faith in the neutrality of their data. They were concerned above all with the creation and distribution of wealth, issues to which machine power and a rising entrepreneurial class lent particular urgency. Within the new industrial order, relations between employer and employee were magnified, partly because of the sheer number of workers which successful entrepreneurs could hire, partly because trade cycles and frequent bankruptcies created problems of unemployment. Increasingly Villermé's work forced him to come to grips with much more than simple mortality statistics.

He began with the army and ended with society at large. In between, however, came a series of studies on prisons: their social functions, economics and the health problems they created. Recent works by Michel Foucault, Michael Ignatieff and David Rothman have alerted us to the radical change in the early nineteenthcentury philosophy of prisons. No longer to be simply coercive or custodial, penitentiaries were to be institutions of reform, instilling in their inmates a new sense of social responsibility and re-training them to take their place in society. The reality was often different, and Villermé's researches revealed appalling conditions and staggering mortalities in many Paris prisons. His book, published in 1820 , alerted those who would take notice to the horrors of life behind locked doors. It also gave Villermé his first extended taste of statistical investigation. By the $1820 \mathrm{~s}$, however, the whole of Paris had become his oyster, and for almost two decades he busied himself with two related, seemingly simple questions: Why did people in cities die sooner, on average, than people in the countryside? Why did poor people, on average, die earlier than rich ones?

The answers Villermé provided changed a bit over the years as he sharpened his analytical tools and refined his data. The cholera epidemic of 1832 gave him a particularly striking opportunity to examine differential mortality ("Inequality before death", Coleman calls it) and he came increasingly to doubt the simple environmental explanations which eighteenthcentury doctors had proposed. More fundamental, he discovered, was the brute fact of income: not simply where you lived, but how much money you had to pay for food, clothing and shelter. It may seem a banal conclusion, but it had polemical consequences of considerable magnitude in the 1830 s.

Villermé's social diagnosis, however, was bolder than his therapeutics. He campaigned hard for legislation protecting children from industrial exploitation, but, for the rest, social melioration would come not through changes in the ownership of the means of production, but through individual change of heart. Workers must learn sobriety and reliability, masters must cultivate benevolence and philanthropy. $\mathrm{He}$ accepted the existing social order, rather than, like his contemporaries Marx and Engels, wishing to change it.

These and other themes are lucidly discussed in Coleman's book, which reminds us that concern over public health was not a British monopoly and examines in illuminating detail the ideological dimensions of social statistics and social medicine. It is a study of the origins of our modern, numerical society. At a time when the philosophy of the welfare state is being challenged, it also has a poignant topicality.

W.F. Bynum is at the Wellcome Institute for the History of Medicine, London.

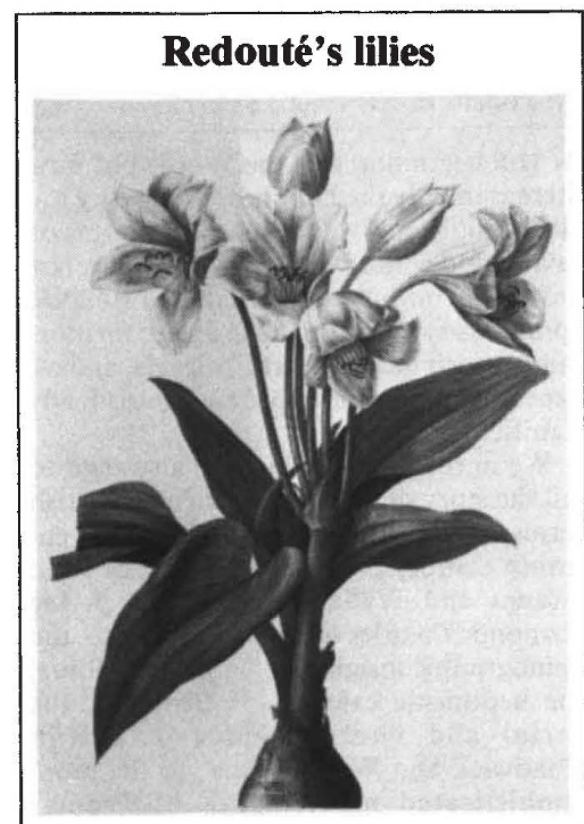

THE illustration - of Crinum jagus, an African amaryllid - is taken from Lilies and Related Flowers, recently published by Overlook Press in the United States and Michael Joseph in Britain. The book contains reproductions of about a hundred plates from nearly five hundred first published from 1802 to 1816 in the eight large volumes of Pierre-Joseph Redouté's Les Liliacées, a glorious series which has been oddly overshadowed by the fame of his paintings of roses. The plates are printed in colour, about half the size of the originals, and are accompanied by notes on the history, horticulture and taxonomy of the plants figured, contributed by Brian Mathew. A short account of Redoutés career and a bibliographical note on the original edition complete an attractive book. Price is \$60, f19.95. Sandra Raphael

\section{Re-scattering theory}

\section{Colin Wilkin}

Scattering Theory of Waves and Particles, 2nd Edn. By Roger G. Newton. Pp.740. ISBN 0-387-10950-1. (Springer-Verlag: 1982.) DM98, $\$ 43.60$.

A GENERATION of physicists studied quantum scattering theory from Mott and Massey's The Theory of Atomic Collisions (first published by Oxford University Press, in 1933), but in the mid-1960s two very useful books appeared which largely took over this role. Of the two, Collision Theory by Goldberger and Watson (Wiley, 1964) was the more physical whereas Roger Newton stressed the formal aspects of the subject and in particular the connection with classical scattering of particles and electromagnetic waves.

Many important papers have been written since then and in the new edition Newton has added a thousand new references. I must, however, confess to being rather disappointed that he has modified the text so little in response to this more recent work. To quote but one example, much of the prolific data on medium energy proton-nucleus scattering has been analysed within the framework of the eikonal approximation. The corrections to this approach and the relationship to the WKB method have been elucidated in a series of remarkable papers by Wallace but the only mention of them is to be found in the bibliography.

Major changes have been made in the sections on the three-body problem, where the original treatment was insufficient in view of modern developments, and on the three-dimensional analysis of potential scattering. The discussion on the inverse scattering problem, where one attempts to construct the potential from physical input such as phase shifts, has been much extended though it cannot compete with the specialist monograph such as Chadan and Sabatier's Inverse Problems in Quantum Scattering Theory (SpringerVerlag, 1977) which contains a long historical introduction by Newton!

Perhaps I am expecting far too much from a single book: even in the first edition Newton eschewed the suggestion that it should be considered as an encyclopaedia of scattering theory and this is even less feasible now. There are many attractive parts to the work such as the comparison of the treatment of rainbow and glory scattering of light, classical and quantum particles which is so illuminating for heavyion scattering. And then there are all those invaluable references. All in all I expect that it will remain a source-book where even experts will go to see things done "properly".

Colin Wilkin, Reader in Physics at University College London, is Honorary Editor of Journal of Physics G: Nuclear Physics. 